\title{
Semi-circular Slotted Monopole Antenna for Future Ultra-Wideband Applications
}

\author{
Srikanth Itapu \\ Asst. Professor, CVR College of Engineering/ ECE Department, Hyderabad, India \\ Email: sri.hydblues@cvr.ac.in
}

\begin{abstract}
Semi-circular slotted monopole antennae are investigated for IoT based ultra-wideband (UWB) applications. The studied antennae are compact and of small size $(40 \mathrm{~mm} x$ $30 \mathrm{~mm} \times 1.53 \mathrm{~mm})$ with a $50 \Omega$ co-planar waveguide $(\mathrm{CPW})$ - feed line. The conventional circular disc monopole antenna impedance bandwidth is improved by introducing multiple cuts on the circular disc. Three designs are examined and compared to the classical circular monopole design: iteration 1, iteration 2 and the proposed antenna with nine semi-circular rings. The proposed antenna offers the measured impedance bandwidth from 3.5 $\mathrm{GHz}$ to $60 \mathrm{GHz}$ and beyond, which is comparatively 6 times of normally achieved by conventional antenna. The measured radiation patterns of semi-circular rings antenna are presented in both $\mathrm{H}$ - and $\mathrm{E}-$ plane.
\end{abstract}

Index Terms: Microstrip antenna, Monopole antenna, CPWfeed, UWB system.

\section{INTRODUCTION}

Ultra-wideband (UWB) communication systems have the advantages of low power consumption, high-speed data rate etc [1]. UWB components such as printed microstrip antennas are proved to be a great choice for present day IoT systems due to small size, low cost, and ease of fabrication and integration in microwave circuits [2]. With Co-Planar Waveguide (CPW)- feed, parameters such as broader frequency bandwidth, greater impedance matching, minimal loss in radiation, and lower dispersion [3-4] are achieved. Over the past few years, CPW-feed UWB antenna designs [56] have gained a lot of attention and reported in the literature but significantly differ primarily by the conductor and the ground plane configuration and shapes.

In [7], the CPW-feed UWB antenna proposed is based on circular disc conductor, and a partial rectangular ground plane. The antenna in [8] consists of a step-typed monopole conductor with a step-slope ground plane. In [9], the antenna is designed as an open annulus strip as ground plane and an open crescent patch in the inner space of the annulus as a radiating element. In [10], the authors introduce annular slot and round corners into the ground and use a round- edged bowtie-shaped conductor. All these antennas predominantly offered an impedance bandwidth of upto $11 \mathrm{GHz}$, which satisfies the present FCC UWB requirement. For future UWB system at higher frequency beyond $11 \mathrm{GHz}$ [11], there is a necessity of an ultra-compact antenna which can cover present as well as future UWB systems. From [12-14], it is evident that the antenna structure offers wide bandwidth performance.

In this paper, we present the UWB antenna with nine cuts in circular disc. The study is primarily aimed to extend the upper limit of the FCC standard to a higher level for future UWB applications. Fractal geometry has been incorporated for this use. The basic circular monopole design is compared with a fractal structure of five concentric semi-circular cuts of 0.2 $\mathrm{mm}$ width with an increment in the radius by $1.0 \mathrm{~mm}$ from 1.0 $\mathrm{mm}$ to $5.0 \mathrm{~mm}$ and another fractal structure of nine semicircular cuts of $0.2 \mathrm{~mm}$ with an increment in the radius by 1.0 $\mathrm{mm}$ from $1.0 \mathrm{~mm}$ to $9.0 \mathrm{~mm}$ as shown in Fig. 1. The dimensions of the antennae are $40.0 \mathrm{~mm} \times 30.0 \mathrm{~mm}$ on substrate thickness of $1.53 \mathrm{~mm}$ and dielectric constant (FR-4 substrate) $\varepsilon r=4.3$.

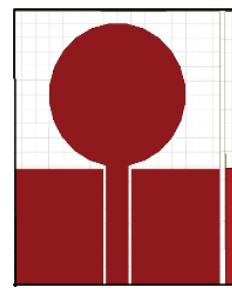

(a)

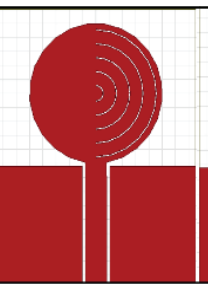

(b)

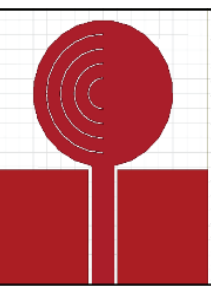

(c)
Figure 1. Geometry of three antenna design.

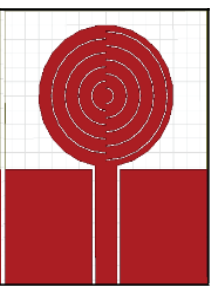

(d)

\section{Antenna Geometry}

The proposed antenna design with concentric circular rings is derived from the classical monopole design. Fig. 1(a) is purely a circular monopole antenna with rectangular ground plane. In Fig. 1(b), semi-circular rings are incorporated with five cuts each of thickness $0.2 \mathrm{~mm}$ subsequent radii ranging from $1.0 \mathrm{~mm}$ to $5.0 \mathrm{~mm}$ (Iteration 1). In Fig. 1(c), four semicircular rings with radii ranging from $1 \mathrm{~mm}$ to $4 \mathrm{~mm}$ are incorporated (Iteration 2). Such concentric turns increase the magnetic confinement of the microwave signal [15] from the source through the SMA connector. Finally, the proposed antenna design is presented in Fig. 1(d), which is a culmination of both the iterations 1 and 2 .

\section{Critical Design Parameters}

The three designs have been simulated. The simulation results are shown in Fig. 2. It is observed from Figure 2, that the first resonance occurs at $3.5 \mathrm{GHz}$ for the circular monopole, and at $3.2 \mathrm{GHz}$ for both the iterative structures (i.e iteration 1 and 2). The return loss of the all four designs are compared upto $60 \mathrm{GHz}$ range. It is evident that the effect of fractal geometry comes into picture for enhancing the upper frequency limit with design 2 and design 3 respectively. This 
is because each semi-circular cut adds up to the resonance frequencies, thus extending the spectrum. The asymmetrical cuts effect the higher frequency side by adding up each of the resonance frequencies resulting out of each cut. Hence, the upper limit of the spectrum is increased to $60 \mathrm{GHz}$.

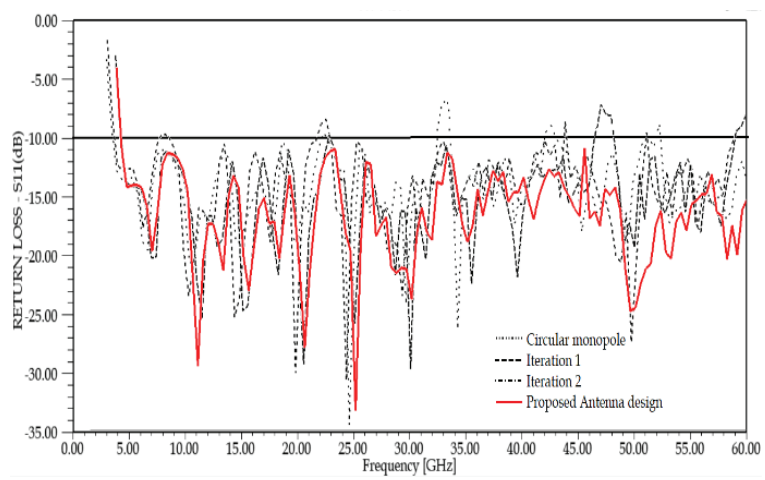

Figure 2. Simulated return loss of three antenna designs.

The proposed antenna was fabricated and the return loss was measured using a Rohde \& Schwarz Vector Network Analyser with a frequency range from $100 \mathrm{MHz}$ to $60 \mathrm{GHz}$. The photograph of this antenna is shown in Fig. 3. The experimental results are shown in Fig. 4 and shows a good correlation to the simulated data.

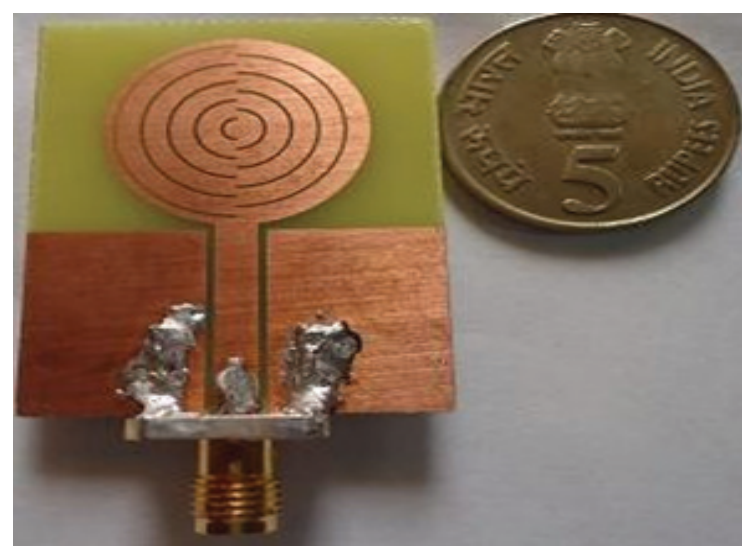

Figure 3. Photograph of fabricated antenna.

The measured impedance bandwidth of this antenna is achieved from $3.5 \mathrm{GHz}$ to $40 \mathrm{GHz}$ beyond the required. There is deviation of the measured and simulated results. This is because of Low quality of SMA connector used as well as fabrication constraints, uncertainty in dielectric constant, thickness of the substrate. The SMA connector has not been considered during simulation. This is because of computational time taken by HFSS software. Also, for the convenience and repetition of the measured data, we have taken enough care to present the experimental retune loss by measuring it randomly at two different times.

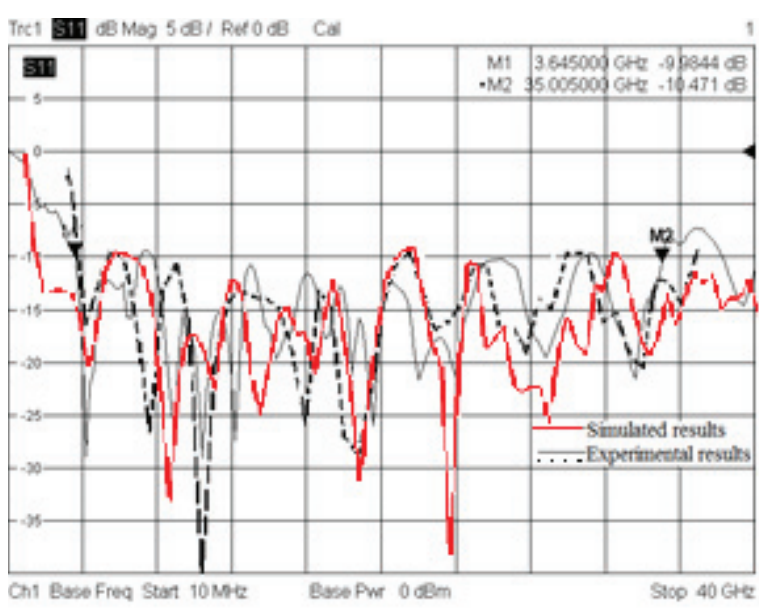

Figure 4. Measured and Simulated results of antenna with nine cut antenna.

\section{Current Distribution}

The current distributions of all the four antenna designs circular monopole, iteration 1, iteration 2 and the final proposed antenna are presented in this section at the frequencies $15 \mathrm{GHz}, 30 \mathrm{GHz}, 45 \mathrm{GHz}$ and $60 \mathrm{GHz}$ shown in Fig. 5 to 8.
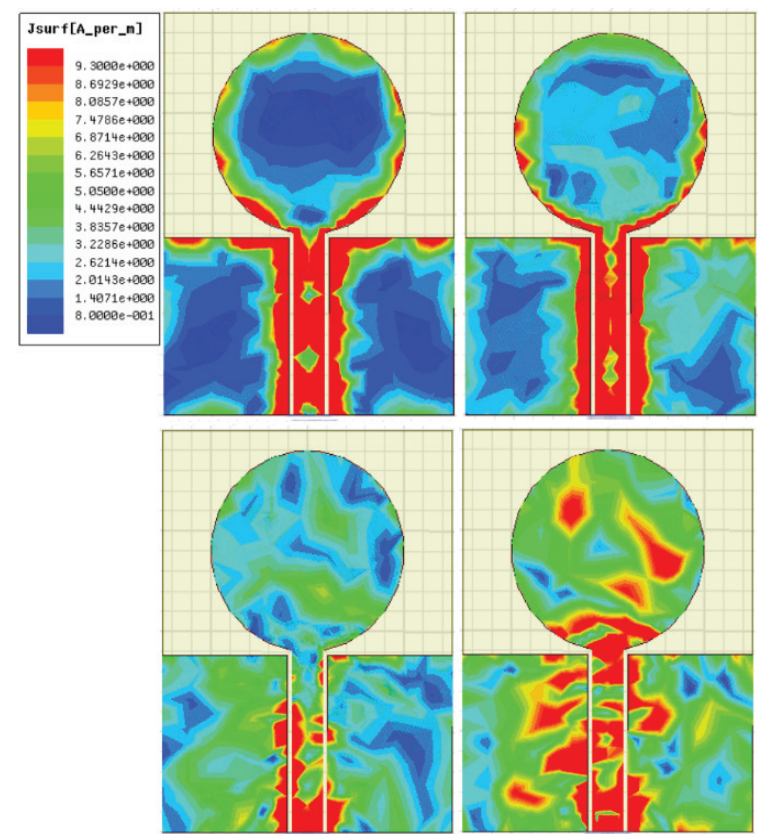

Figure 5. Current distributions of classical monopole at $15 \mathrm{GHz}$, $30 \mathrm{GHz}, 45 \mathrm{GHz}$, and $60 \mathrm{GHz}$.

For the circular monopole, three minima can be observed at 15.0 GHz which corresponds to the first three resonance frequencies of the design. The first minima (means first resonant frequency) indicates resonance mode which can be seen by current maxima over the feed line and ground plane. As the frequency is increased, the resonances merge and it becomes impossible to distinguish between number of 
minima. The current is symmetrically distributed from the feedline through the circumference of the circular patch at frequencies $15.0 \mathrm{GHz}, 30.0 \mathrm{GHz}, 45.0 \mathrm{GHz}$ and $60 \mathrm{GHz}$. Increase in the frequency results increase in current distribution in the ground plane. It is because of the increase in the minima that the power flow to the circular patch is minimized.

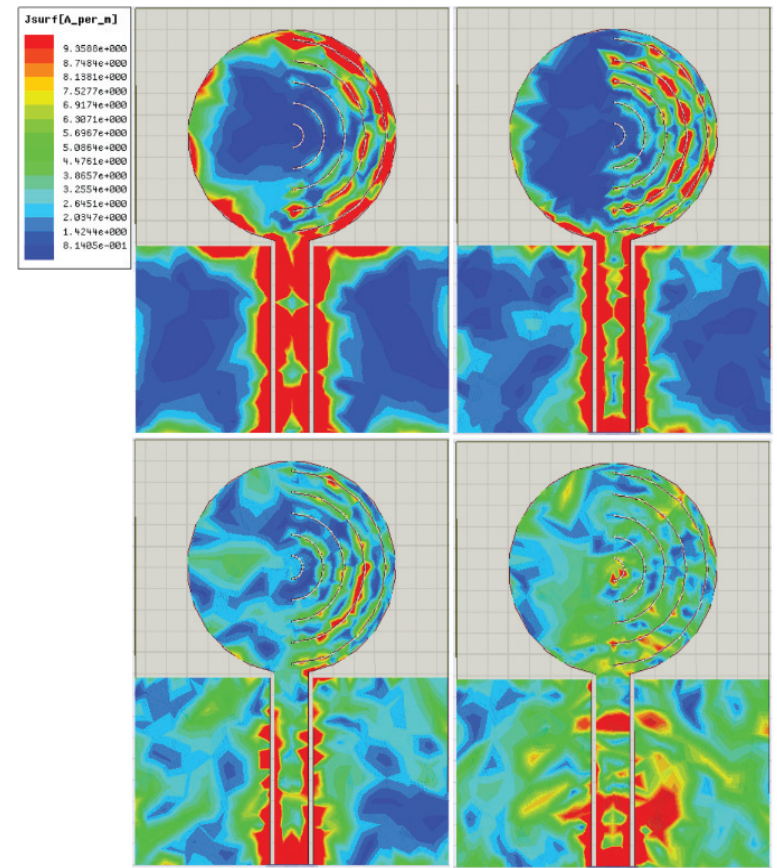

Figure 6. Current distributions of Iteration 1 design at $15 \mathrm{GHz}, 30 \mathrm{GHz}$, $45 \mathrm{GHz}$, and $60 \mathrm{GHz}$.

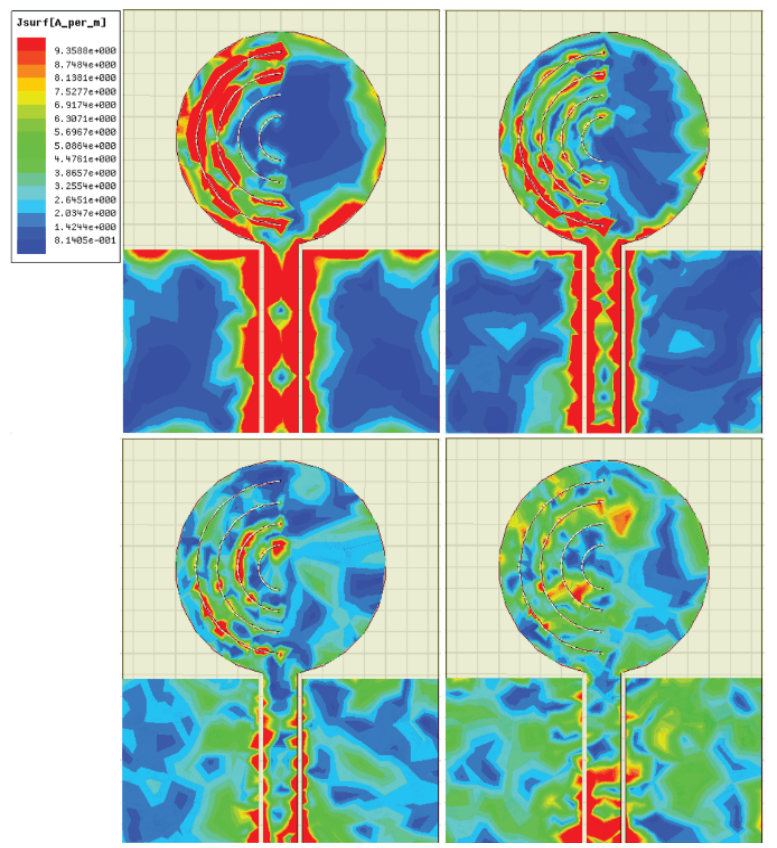

Figure 7. Current distributions of Iteration 2 design at $15 \mathrm{GHz}, 30 \mathrm{GHz}$, $45 \mathrm{GHz}$, and $60 \mathrm{GHz}$.
For the Iterative designs 1 and 2 (Fig. 6 and 7), the first two minima can be observed at $15.0 \mathrm{GHz}$ which corresponds to the first resonance frequency of the design. The current is symmetrically distributed from the feedline through the circumference of the circular patch and along the fractal cuts at frequencies $15.0 \mathrm{GHz}, 30.0 \mathrm{GHz}, 45.0 \mathrm{GHz}$ and $60.0 \mathrm{GHz}$. The asymmetrical cuts effect the higher frequency side by adding up each of the resonance frequencies resulting out of each cut. Hence, the upper limit of the spectrum is increased to $45.0 \mathrm{GHz}$ for design 2 and $63.5 \mathrm{GHz}$ for design 3 .

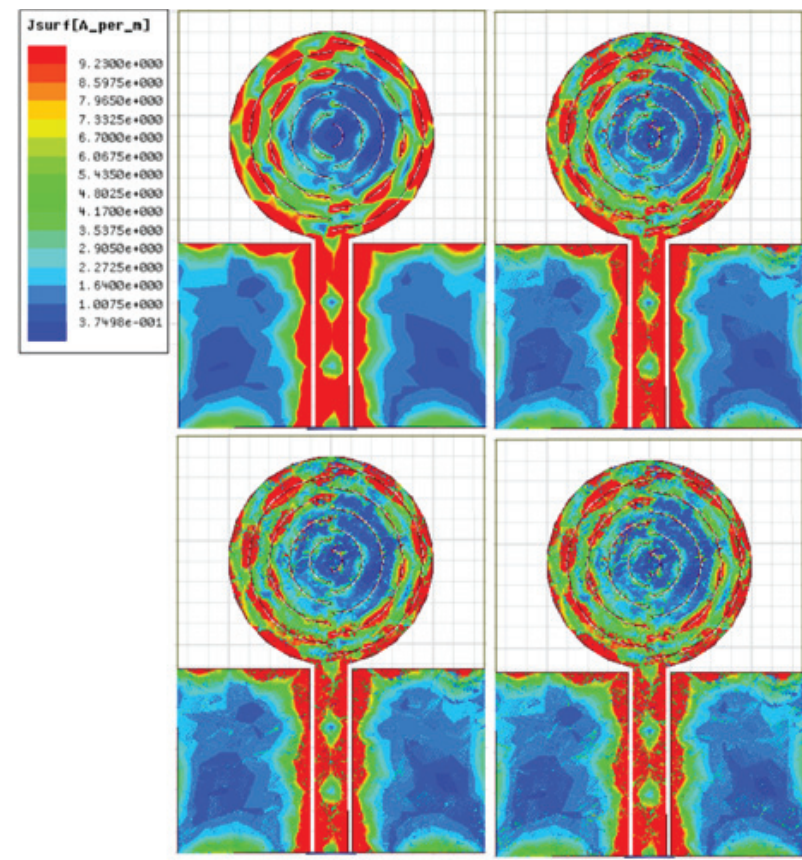

Figure 8 . Current distributions of nine cuts at $15 \mathrm{GHz}, 30 \mathrm{GHz}, 45 \mathrm{GHz}$, and $60 \mathrm{GHz}$

From Fig. 8, it is evident that the circular rings indeed effect and influence the current distribution (seen in red at the edges of the rings in Fig. 8). This current accumulation results in a smooth impedance bandwidth ranging from $3.5 \mathrm{GHz}$ to 60 GHz.

\section{Measured Radiation Patterns}

The E- plane and H-plane radiation patterns of proposed antenna have been measured at selective frequencies shown in Fig. 9 and 10. The E-plane radiations are measured in anechoic chamber at $5 \mathrm{GHz}, 10 \mathrm{GHz}, 20 \mathrm{GHz}, 30 \mathrm{GHz}, 40 \mathrm{GHz}, 50 \mathrm{GHz}$, $60 \mathrm{GHz}$. The $\mathrm{E}$-plane radiation patterns throughout the band are bidirectional as shown in Fig. 9. Similarly, H - plane radiation patterns are also measured at various frequencies like 3.5GHz, $4.5 \mathrm{GHz}, 6 \mathrm{GHz}, 8 \mathrm{GHz}, 11 \mathrm{GHz}$ and $18 \mathrm{GHz}$ as shown in Fig. 10. The nature of H-plane patterns is nearly omnidirectional. It is also observed, as the frequency increases, the radiation patterns are slightly deteriorated. It may be because of the edge reflections, FR4 lossy substrate and fractal nature of antenna and generation of higher mode at higher frequencies. 

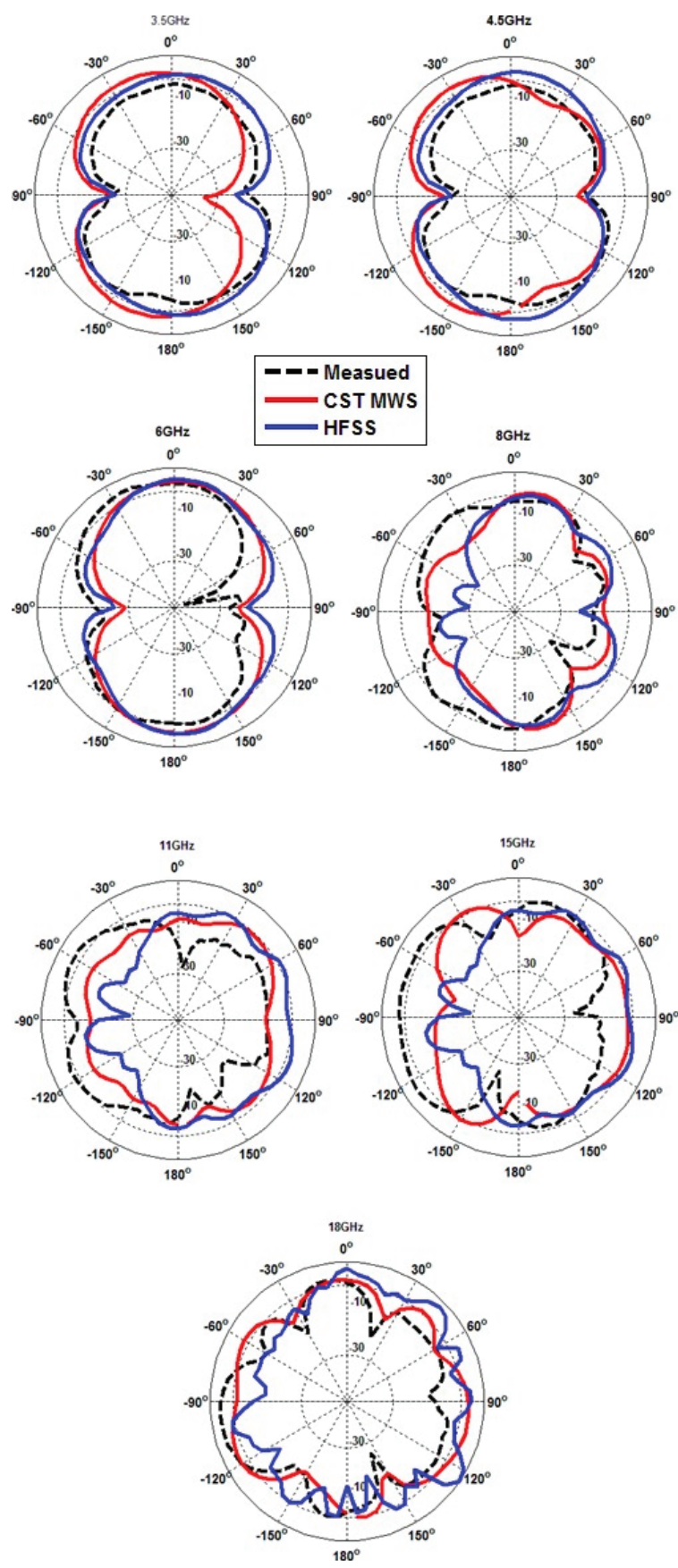

Figure 9. Measured E-plane Radiation patterns at 5, 10, 20, 30, 40, 50 and $60 \mathrm{GHz}$ frequencies.
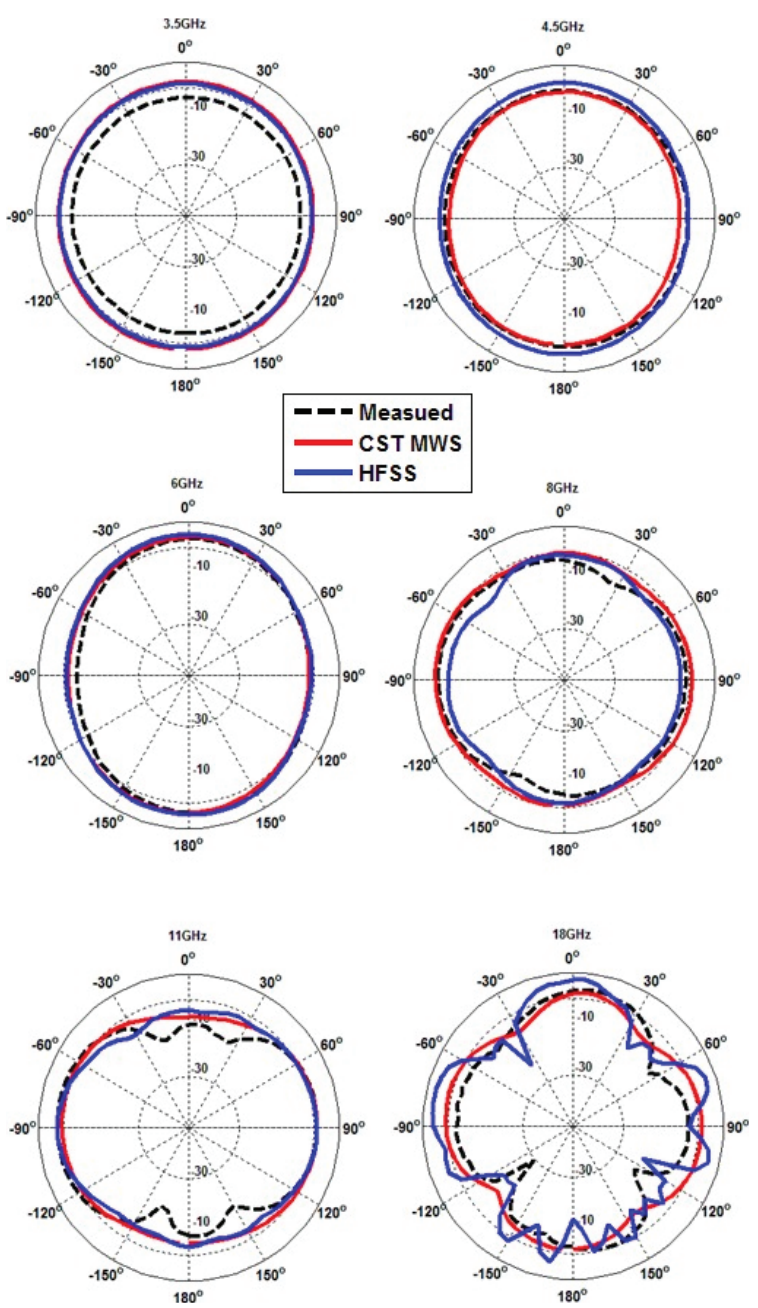

Figure 10. Measured H-plane Radiation patterns at 10, 20, 30, 40, 50 and $60 \mathrm{GHz}$ frequencies.

\section{Peak gain and Radiation Efficiency}

The peak gain of the proposed antenna has been measured and compared with simulated gain using HFSS and CST MWS. The peak gain was measured upto $18 \mathrm{GHz}$ because of limitation of availability of reference antenna. A good agreement found between measured and simulated peak gain as shown in Fig. 11. It is noticed from the measured and simulated results, as the frequency increases, the peak gain increases. This is because, at higher frequencies, the receiving area becomes more in comparison to short wavelength. The radiation efficiency of the proposed antenna has also been simulated using HFSS and CST MWS and compared as shown in Fig. 12. From Fig. 12, it is noticed that the radiation efficiency decreases with increase in frequency. This is because of loss increase with 
frequency increase due to high loss tangent of substrate used. It is noticed from Fig. 11 and 12, there is a little difference between the gain and radiation efficiency simulated using HFSS and CST MWS. This difference is because of different numerical techniques used in commercial software.

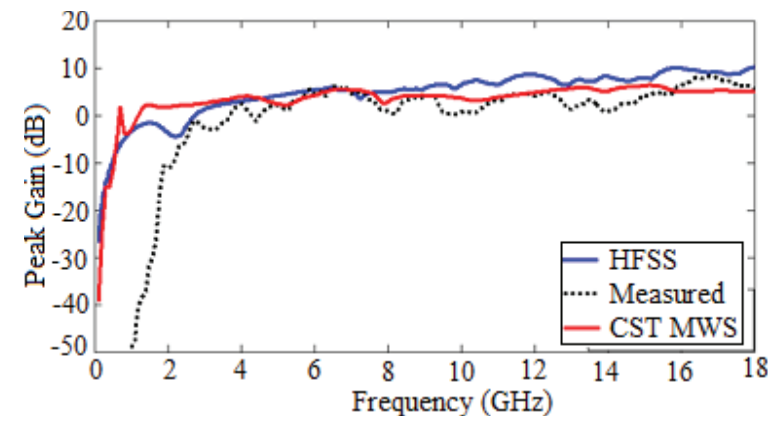

Figure 11. Simulated and measured gain.

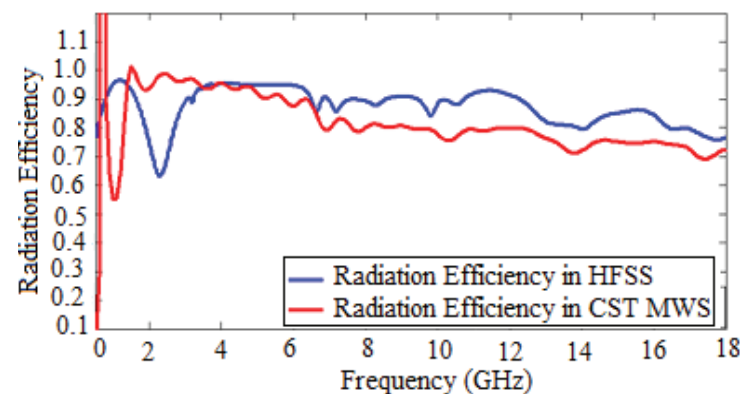

Figure 12. Simulated Radiation Efficiency of the proposed antenna.

\section{Conclusions}

A compact UWB antenna with semi-circular ring structures with CPW feed have been designed and experimentally validated for ultra-wideband frequency from $3.5 \mathrm{GHz}$ to $60 \mathrm{GHz}$. The measured radiation patterns of this antenna with circular rings are omni- directional in H-plane and bidirectional in E- plane. This antenna is simple to design, easy to fabricate, compact in size and easy to integrate with MIC/MMICs devices. Such an antenna can be used for future UWB applications, smart IoT applications and medical imaging.

\section{REFERENCES}

[1] First Report and Order, "Revision of Part 15 of the Commission's Rule Regarding Ultra-Wideband Transmission System FCC02-48,"Federal Communications Commission, 2002.

[2] C.A. Balanis, Antenna Theory, Analysis and Design, Wiley, Hoboken, USA, 2005.

[3] D.-C. Chang, B.-H. Zeng, and J.-C. Liu, "CPW- fed circular fractal slot antenna design for dual- band applications", IEEE Trans. Antennas Propag., Vol. 56, No. 12, pp. 3630- 3636, Dec.2008.
[4] A. U. Bhobe, C. L. Holloway, M. Piket-May, and R. Hall, "Wide-band slot antennas with CPW feed lines: hybrid and log-periodic designs", IEEE Trans. Antennas Propag., Vol. 52, No. 10, pp. 2545-2554, Oct. 2004.

[5] I. Srikanth and Raj Kumar, "On the design of apollonian packing fractal antenna for UWB applications", Microwaves \& RF, 2012.

[6] Raj Kumar and I. Srikanth, "Design of apollonian gasket ultrawideband antenna with modified plane", Microwave and Optical Tech. Lett., vol. 54, no. 8, 2012.

[7] J. Liang, L. Guo, C.C. Chiau, X. Chen and C.G. Parini, "Study of CPW-fed circular disk monopole antenna for ultrawideband applications", IEE Proc. Microwaves, Antennas \& Propag., Vol. 152, No. 6, pp. 520-526, Dec. 2005.

[8] J.-Y. Jan, J.-C. Kao, Y.-T. Cheng, W.-S. Chen, and H. M.Chen, "CPW-fed wideband printed planar monopole antenna for ultra-wideband operation", Proc. 2006 IEEE AP$S$ International Symposium and URSI National Radio Science Meeting, Albuquerque, New Mexico, pp. 16971700, 9-14 July 2006

[9] M.-E. Chen and J.-H. Wang, "CPW-fed crescent patch antenna for UWB applications", Electronics Letters, Vol. 44, No 10, pp. 613-614, May 2008.

[10] L. Zhao, C.-L. Ruan, and S.-W. Qu, "A novel broadband slot antenna fed by CPW", Proc. 2006 IEEE AP-S International Symposium and URSI National Radio Science Meeting, Albuquerque, New Mexico, pp.2583-2586,9-14 July 2006.

[11] M. N. Srifi, S. k. Podilchak and Yahia M. m. Antar" Compact Disc monopole antennas for current and future ultrawideband (UWB) applications",IEEE Trans. on antennas and propagation, vol. 59, No. 12, Dec. 2011, pp. 4470-4480.

[12] S. Tripathi, A. Mohan and S. Yadav, "A Compact Koch Fractal UWB MIMO Antenna with WLAN Band-Rejection", IEEE Trans. Antennas \& Prop., Vol. 14, pp. 1565-68, Aug. 2015.

[13] A. Amini, H. Oraizi and M.A.C. Zadeh, "Miniaturized UWB Log-Periodic Square Fractal Antenna", IEEE Trans. Antennas \& Prop., Vol. 14, pp. 1322-25, Mar. 2015.

[14] T. Ali, B.K. Subhash and R.C. Biradar, "A Miniaturized Decagonal Sierpinski UWB Fractal Antenna”, PIERS C, vol. 84, pp. 161-174, 2018.

[15] S. Itapu, D.G. Georgiev and V. Devabhaktuni, "Improvement in inductance and Q-factor by laser microstructuring of ferromagnetic on-chip thin film inductors", $J$. of Elec.Mag. Waves and Appl., vol. 29, no. 12, pp. 1547-1556, 2015. 